\title{
Thymol/cyclodextrin inclusion complex nanofibrous webs: Enhanced water solubility, high thermal stability and antioxidant property of thymol
}

\author{
Asli Celebioglu, Zehra Irem Yildiz, Tamer Uyar* \\ Institute of Materials Science \& Nanotechnology, UNAM-National Nanotechnology Research Center, Bilkent University, Ankara 06800, Turkey
}

\section{A R T I C L E I N F O}

\section{Keywords:}

Cyclodextrin

Electrospinning

Thymol

Inclusion complex

Nanofibers

Antioxidant property

Water-solubility

Temperature stability

\begin{abstract}
A B S T R A C T
The development of novel nanomaterials that provide an efficient encapsulation and protection for the active food additives is one of the main focuses of current research efforts at food application areas. From this point of view, in this study, nanofibrous webs from inclusion complexes (IC) of modified cyclodextrins (hydroxypropyl- $\beta$ cyclodextrin (HP $\beta C D)$, hydroxypropyl- $\gamma$-cyclodextrin (HP $\gamma \mathrm{CD}$ ) and methyl- $\beta$-cyclodextrin $(\mathrm{M} \beta \mathrm{CD})$ ) and essential oils compound (i.e. thymol) was produced through electrospinning technique. While pure thymol has a highly volatile nature, the volatility of thymol was effectively suppressed by the inclusion complexation and $\sim 88-100 \%(\mathrm{w} / \mathrm{w})$ of thymol was preserved in electrospun thymol/cyclodextrin inclusion complex nanofibers (Thymol/CD-IC NF). The aqueous solubility enhancement for hydrophobic thymol was demonstrated by phase solubility diagram which also suggested the 1:1 $\mathrm{M}$ inclusion complexation between thymol and CD molecules. Besides, Thymol/CD-IC NF displayed quite fast disintegration in water compared to poorly water soluble thymol. By inclusion complexation, high temperature stability for volatile thymol was achieved for Thymol/CD-IC NF samples. The loading of thymol in Thymol/CD-IC NF conferred DPPH radical scavenging ability to these nanofibrous webs. So, the Thymol/CD-IC NF have shown antioxidant activity along with enhanced water solubility and high thermal stability of thymol. In brief, encapsulation of essential oil compounds such as thymol in electrospun CD-IC nanofibers can promote its potential application in food and oral-care products by associating the large surface area of nanofibrous webs along with CD inclusion complexation which provides enhanced water solubility and antioxidant property, and high temperature stability for thymol.
\end{abstract}

\section{Introduction}

Electrospun nanofibers/nanowebs have an increasing importance for the food and biomedical applications owing to their encapsulation property of active agents such as food additives and drugs (Mittal, Pérez-Mariá, Fabra, Lagarón, \& López-Rubio, 2012; Moomand \& Lim, 2014; Noruzi, 2016; Wen, Wen, Zong, Linhardt, \& Wu, 2017). Electrospinning technique enables to produce nanofibers/nanowebs along with high surface-to-volume ratio, highly porous structure, and unique properties in which these electrospun nanofibers/nanowebs can be used in a variety of areas including healthcare, environmental, energy and food, etc. (Cavaliere, 2015; Uyar \& Kny, 2017; Wendorff, Agarwal, \& Greiner, 2012). The production of nanofibers from polymeric materials by using organic solvents was considered as one of the main drawback of electrospinning techniques which can cause toxicity and cost concerns for the healthcare and food applications. Even, water soluble polymers can be appreciated as an alternate solution to this problem; there still exists another issue need to be addressed from the point of food applications during the encapsulation of active compounds having high volatility. Such that, as we have observed in our recent studies, the mere polymeric nanofibers are not exactly sufficient to preserve volatile additives (such as menthol, vanillin, geraniol, eugenol, allyl isothiocyanate) during or after the electrospinning process (Aytac, Dogan, Tekinay, \& Uyar, 2014; Kayaci, Ertas, \& Uyar, 2013; Kayaci, Sen, Durgun, \& Uyar, 2014; Kayaci \& Uyar, 2012; Uyar, Hacaloglu, \& Besenbacher, 2009a, 2009b, 2011), on the other hand, the molecular encapsulation of these active compounds into cyclodextrin molecules by inclusion complexation was utilized as a feasible approach to reduce their volatility in these studies.

Cyclodextrins (CD) are well-known cyclic oligosaccharides which are produced from enzymatic degradation of starch. CD have truncated cone-shape molecular structures having relatively hydrophobic cavity which enable to form non-covalent host guest inclusion complexation (IC) with variety of active compounds (Del Valle, 2004; Szejtli, 1998). Food, cosmetic additives and drugs are high potential guest molecules which are favourably encapsulated in CD molecules. The CD-IC offer

\footnotetext{
* Corresponding author.

E-mail address: tamer@unam.bilkent.edu.tr (T. Uyar).
} 
water-solubility enhancement, stabilization against degradation and oxidation, controlled and/or sustained release for the volatile and hydrophobic active compounds (Del Valle, 2004; Marques, 2010; Szejtli, 1998; Szente \& Szejtli, 2004). Both the non-toxic nature and the unique properties acquired by inclusion complexation make CD-IC attractive for numerous formulations of food, pharmaceutical and cosmetic products (Ciobanu, Landy, \& Fourmentin, 2013; Del Valle, 2004; Szejtli, 1998). Recently, we performed studies on the electrospinning of CD-IC incorporated polymeric nanofibers to eliminate the volatility problem of the active compounds. Yet, when CD-IC is incorporated in electrospun polymeric matrix, the weight loading of these compounds is limited up to $\sim 5 \%(\mathrm{w} / \mathrm{w}$, with respect to fiber matrix) (Aytac et al., 2014; Aytac, Keskin, Tekinay, \& Uyar, 2017; Aytac, Kusku, Durgun, \& Uyar, 2016a, 2016b; Kayaci \& Uyar, 2012; Kayaci, Ertas et al., 2013; Kayaciet al., 2014; Kayaci, Umu, Tekinay, \& Uyar, 2013; Uyar et al., 2009a, 2009b, 2011) because, the electrospinning of uniform nanofibers is not quite possible from polymeric solution incorporating of higher amount of CD-IC $(50 \% \mathrm{w} / \mathrm{w}$, which corresponds to 3 to $5 \%$ active agent if 1:1 $\mathrm{M}$ ratio is considered). Fortunately, in our very recent studies, we were able to obtain electrospun nanofiber matrix containing higher amount of active agents (loading of $\sim 10-15 \%$, w/w) by the electrospinning of pure CD-IC systems without using an additional polymeric matrix (Aytac et al., 2016a, 2016b; Aytac, Yildiz, KayaciSenirmak, Tekinay, \& Uyar, 2017; Celebioglu, Kayaci-Senirmak, İpek, Durgun, \& Uyar, 2016; Celebioglu \& Uyar, 2017). By this approach, we are also able to obtain higher fiber throughput compare to polymeric systems since, while the polymeric nanofibers are usually obtained from 5 to $25 \%(\mathrm{w} / \mathrm{v})$ polymer concentrations, CD-IC nanofibers are electrospun from 120 to $160 \%(\mathrm{w} / \mathrm{v})$ concentrated CD-IC systems due to extremely high water solubility of modified CD.

The phenolic compound; thymol (2-isopropyl-5-methylphenol), extracted from thyme, is one of the very efficient antioxidant found in essential oils and it is classified as GRAS by the FDA (Kfoury et al., 2016). Due to its noticeable antioxidant property, non-toxic and antimutagenic feature, thymol is widely used in food, medical and cosmetic industry as fragrance/flavoring agent or natural preservatives which enable an enhanced shelf-life (Bakkali, Averbeck, Averbeck, \& Idaomar, 2008; Kfoury et al., 2016; Llana-Ruiz-Cabello et al., 2015). This white crystalline compound can inhibit lipid peroxidation prompted by reactive oxidase system (ROS) owing to its radical scavenging property (Bakkali et al., 2008; Li, Yin, Yang, Tang, \& Wei, 2012) However, the highly volatile nature and low water-solubility make desire the encapsulation of this compound by proper approaches to eliminate these challenges during their practices/processing and to enhance their efficiency (Marques, 2010).

Briefly, encapsulation of essential oils (EO) in nano-carriers can be structured by a variety of material having different design. Polymerbased and lipid-based nano-systems for the encapsulation of EO such as; nanoparticles, nanocapsules, nanoemulsions, micelles, liposomes are applied to eliminate the drawbacks of EO (volatility and low solubility) and to protect these active compounds against environmental factors (light, oxygen, moisture etc.) (Bilia et al., 2014; Fathi, Mozafari, \& Mohebbi, 2012). In the recent years, electrospinning is becoming an attractive alternative nano-encapsulation approach for pharmaceuticals and food additives (Uyar \& Kny, 2017; Wen et al., 2017). Electrospinning is a simple and cost-effective technique which enables appreciable flexibility for selecting materials and provides higher loading capacity for active compounds. Moreover, it is possible to produce nanofibrous encapsulation materials with high surface area and high porosity by this technique. Thus, efficient encapsulation systems can be developed from electropsun nanofibers for practical applications in pharmaceutics and foods (Lagarón \& López-Rubio, 2012; Uyar \& Kny, 2017; Wen et al., 2017). Here, electrospinning of thymol/cyclodextrin inclusion complex nanofibers (Thymol/CD-IC NF) was performed without the use of any additional fiber forming polymeric component. The inclusion complexes were prepared by using thymol and three modified CD types (hydroxypropyl- $\beta$-cyclodextrin (HP $\beta C D$ ), hydroxypropyl- $\gamma$-cyclodextrin $(\mathrm{HP} \gamma \mathrm{CD})$ and methyl- $\beta$-cyclodextrin $(\mathrm{M} \beta \mathrm{CD}))$. The free-standing nanofibrous webs of Thymol/CD-IC NF samples were characterized by various techniques including SEM (morphological); ${ }^{1} \mathrm{H}-\mathrm{NMR}$, XRD, FTIR (structural) and TGA (thermal). Beside the efficient preservation of thymol in Thymol/CD-IC NF, fast water-disintegration and enhanced water-solubility were also achieved for Thymol/CD-IC NF. Thymol/CDIC NF have also shown high thermal stability and effective antioxidant property as a result of inclusion complexation of thymol with cyclodextrins.

\section{Materials and methods}

\subsection{Materials}

Thymol (98\% purity, Sigma-Aldrich), methanol (extra pure, SigmaAldrich), 2,2-diphenyl-1-picrylhydrazyl (DPPH, Sigma-Aldrich), potassium bromide (KBr, 99\%, FTIR grade, Sigma-Aldrich), deuterated dimethylsulfoxide (d6-DMSO, deuteration degree min. 99.8\% for NMR spectroscopy, Merck) were purchased. The hydroxypropyl- $\beta$-cyclodextrin (HP $\beta C D$ ) (degree of substitution (DS): $\sim 0.6$, Cavasol ${ }^{\circledR} \mathrm{W} 7 \mathrm{HP}$ Pharma), hydroxypropyl- $\gamma$-cyclodextrin $(\mathrm{HP} \gamma \mathrm{CD}) \quad(\mathrm{DS}: \sim 0.6$, Cavasol ${ }^{\oplus} \mathrm{W} 8$ HP Pharma) and methyl- $\beta$-cyclodextrin (MBCD) (DS: 1.6-1.9 Cavasol ${ }^{\oplus}$ W7 M Pharma) which are Food and Drug Administration (FDA) approved were kindly given by Wacker Chemie AG (Germany). All the materials were used as-received. The Millipore Milli-Q ultrapure water system was used for the water used in the experiments.

\subsection{Preparation of samples}

In our previous study (Celebioglu \& Uyar, 2012), we successfully obtained bead-free and uniform nanofibers from three modified $\mathrm{CD}$ types (HP $\beta C D, H P \gamma C D$ and $M \beta C D)$ in water using their $160 \%(w / v$, with respect to solution) highly concentrated solutions. Therefore, in this study, we decided to use this optimized concentration of $\mathrm{CD}$ to produce Thymol/CD-IC nanofibers, as well. First, three modified CD types (HP $\beta C D, H P \gamma C D$ and $M \beta C D$ ) were separately dissolved in water at $160 \%$ concentration ( $1.6 \mathrm{~g}$ of $\mathrm{CD}$ in $1 \mathrm{~mL}$ water). Afterwards, certain amount of thymol was added to these clear CD solutions to have 1:1 M ratio of $\mathrm{CD}$ :Thymol. Then $\mathrm{CD} /$ Thymol solutions were stirred overnight at RT to ensure the complex formation between $\mathrm{CD}$ and thymol molecules (Thymol/CD-IC). Due to the inclusion complexation, insoluble thymol become soluble as well and clear solutions of Thymol/CD-IC were obtained after stirring process. Finally, the electrospinning of Thymol/CD-IC solutions was performed in order to produce nanofibers (Thymol/CD-IC NF). The optimized parameters for the electrospinning process were as follow; applied voltage: $15-20 \mathrm{kV}$, feed rate: $0.5 \mathrm{~mL} / \mathrm{h}$, collection distance: $10-12 \mathrm{~cm}$. For the electrospinning, a plastic syringe (with a metallic needle of $0.4 \mathrm{~mm}$ inner diameter) was loaded with Thymol/CD-IC aqueous systems, and then it was placed horizontally on a syringe pump (KD Scientific, KDS-101, USA). To deposit nanofibrous web on the grounded metal collector covered by aluminium (Al) foil, high voltage was applied using high voltage power supply (AU Series, Matsusada Precision Inc., Japan). The environmental condition during the electrospinning process was set to $25^{\circ} \mathrm{C}$ and $18 \%$ relative humidity. After the electrospinning, electrospun nanofibrous webs of Thymol/CDIC NF were detached from the Al foil and these self-standing nanofibrous webs were dried at RT and then kept in refrigerator (at $4{ }^{\circ} \mathrm{C}$ ). Pure $\mathrm{CD}$ nanofibers without thymol (HP $\beta \mathrm{CD}-\mathrm{NF}, \mathrm{M} \beta \mathrm{CD}-\mathrm{NF}$, and $\mathrm{HP} \gamma \mathrm{CD}-\mathrm{NF}$ ) were also produced for comparative measurements according to our previous report (Celebioglu \& Uyar, 2012). For comparison, the powder forms of Thymol/CD-IC were also prepared by freeze-drying method. For this, three modified $\mathrm{CD}$ types (HP $\beta C D, H P \gamma C D$ and $M \beta C D$ ) were dissolved in water having $160 \%$ (w/v, with respect to solution) $\mathrm{CD}$ concentration, thymol was added to have 1:1 $\mathrm{M}$ ratio of $\mathrm{CD}$ :Thymol and 
the solutions were stirred overnight. The Thymol/CD-IC systems were frozen at $-80{ }^{\circ} \mathrm{C}$ and then they were lyophilized in a freeze-dryer (Labconco) to obtain powder form of Thymol/CD-IC.

\subsection{Characterizations and measurements}

The viscosity of $\mathrm{CD}$ and Thymol/CD-IC aqueous systems was determined using cone/plate rheometer (spindle type CP 20-4, Anton Paar Physica MCR 301) at a constant shear rate of $100 \mathrm{~s}^{-1}$ at $23^{\circ} \mathrm{C}$. Inolab ${ }^{\circledR}$ $\mathrm{pH} /$ Cond 720-WTW was used to measure the solution conductivity of Thymol/CD-IC systems. The morphological examination of CD NF and Thymol/CD-IC NF samples was performed by scanning electron microscopy (SEM, FEI - Quanta 200 FEG). Prior the measurement, nanofibrous webs were put onto SEM stub and sputtered with $5 \mathrm{~nm}$ of Au/Pd (PECS-682) to reduce the charging for a better SEM imaging. The average fiber diameter (AFD) and fiber diameter distribution of the samples were calculated from SEM images of $\sim 100$ fibers.

The proton nuclear magnetic resonance $\left({ }^{1} \mathrm{H}-\mathrm{NMR}\right)$ is a useful technique to calculate the molar ratio of host:guest molecules in CD-IC systems (Ali, Asmat, \& Maheshwari, 2004; Celebioglu et al., 2016; Uyar, Hunt, Gracz, \& Tonelli, 2006). For ${ }^{1} \mathrm{H}-\mathrm{NMR}$ measurement, $20 \mathrm{mg} / \mathrm{mL}$ of each Thymol/CD-IC NF was dissolved in d6-DMSO and the molar ratio of CD:Thymol was calculated from ${ }^{1} \mathrm{H}-\mathrm{NMR}$ results. The ${ }^{1} \mathrm{H}-\mathrm{NMR}$ spectra were recorded at $400 \mathrm{MHz}$ (Bruker DPX-400) and the integration of the chemical shifts $(\delta)$ was calculated by using Mestrenova software. For this, the characteristic peaks of $C D$ at $1.00 \mathrm{ppm}$ for $\mathrm{HP} \beta C D$ and $\mathrm{HP} \gamma \mathrm{CD} ; 4.50-5.00 \mathrm{ppm}$ for $\mathrm{M} \beta C D ; 1.10 \mathrm{ppm}$ for thymol were used to determine the molar ratios between CD (HP $\beta C D, H P \gamma C D$ and $\mathrm{M} \beta \mathrm{CD}$ ) and thymol in Thymol/CD-IC NF. The thermal behavior of pristine CD NF, pure Thymol and Thymol/CD-IC NF samples was studied by thermogravimetric analyzer (TGA, TA Q500, USA). TGA thermograms were recorded under nitrogen atmosphere by heating the samples from $25{ }^{\circ} \mathrm{C}$ to $500{ }^{\circ} \mathrm{C}$ with the heating rate of $20{ }^{\circ} \mathrm{C} / \mathrm{min}$. Fourier transform infrared spectrometer (FTIR) (Bruker-VERTEX70) was also used to get infrared spectra of the samples. For this, samples were firstly blended with potassium bromide $(\mathrm{KBr})$ and pressed as pellets. The scanning (64 scans) were carried out between 4000 and $400 \mathrm{~cm}^{-1}$ with resolution of $4 \mathrm{~cm}^{-1}$. The crystalline structure of samples were evaluated by X-ray diffraction (XRD) (PANalytical X'Pert powder diffractometer) in a range of $2 \theta=5^{\circ}-30^{\circ}$ using $\mathrm{Cu} \mathrm{K \alpha}$ radiation in powder diffraction.

Phase solubility graphs were obtained using Higuchi and Connors methods in aqueous medium (Higuchi \& Connors, 1965). For phase solubility experiment, first of all clear CD solutions were prepared ranging from 0 to $60 \mathrm{mM}$ concentrations. Then, thymol was added to each of these solutions with excess amount and they were stirred for $48 \mathrm{~h}$ at RT to reach equilibrium. Afterwards, $0.45 \mu \mathrm{m}$ membrane filter was used to filter the undissolved thymol crystals in the solutions. The UV-Vis spectroscopy (Varian, Carry 100) measurements at $279 \mathrm{~nm}$ were recorded for the solutions. The experiments were performed in triplicate and average of the measurements was taken into consideration to plot the phase solubility diagrams for the molar concentration of thymol versus molar concentration of $\mathrm{CD}$. By using the same diagrams, the apparent stability constant $\left(\mathrm{K}_{\mathrm{s}}\right)$ of CD-IC were calculated according to the following equation:

$\mathrm{K}_{\mathrm{s}}=$ slope $/ \mathrm{S}_{0}(1-$ slope $)$

where $S_{0}$ is the intrinsic solubility of active agents and Thymol $(\sim 6 \mathrm{mM})$ has quite limited solubility in water (Yalkowsky, He, \& Jain, 2016).

The water solubility of Thymol/CD-IC NF, Thymol/CD-IC powder and Thymol in water was visualized by adding water to Thymol/CD-IC NF $(3 \times 2 \mathrm{~cm})$, Thymol/CD-IC powder and pure Thymol in petri dishes and a vial then, both the photographs and videos were recorded. The samples having the same amount of thymol was used for each case.

Antioxidant performance of samples was followed by 2,2-diphenyl- 1-picrylhydrazyl (DPPH) radical scavenging method. Here, DPPH• solution was prepared in methanol $(75 \mu \mathrm{M})$ and then $200 \mu \mathrm{L}$ of aqueous solutions of Thymol/CD-IC NF and Thymol were mixed with the $2.3 \mathrm{~mL}$ of fresh DPPH• solution. For the concentration dependent antioxidant experiments, $50-4000 \mu \mathrm{g} / \mathrm{mL}$ nanoweb concentration ranges was used, respectively Pure Thymol concentration was kept as the initial Thymol content in Thymol/CD-IC NF system $(\sim 10 \%$ (w/w, with respect to total sample amount)). The Thymol/CD-IC NF were disintegrated in water immediately, on the other hand, we filtered Thymol solution to remove undissolved Thymol parts in the solutions. The dominant absorbance of $\mathrm{DPPH} \cdot$ solution at $517 \mathrm{~nm}$ disappears in the progressing time with addition of sample and so the reduction by antioxidant compound. Sample concentration for the $50 \%$ inhibition (IC50) was determined from the graph plotted inhibition percentage against sample concentration. Afterwards, time dependent reduction of $\mathrm{DPPH} \bullet$ (within $10 \mathrm{~min}$.) was recorded by using UV-Vis spectroscopy (Varian, Carry 100). The experiments were performed three times for the highest nanofiber concentration of samples used for the previous experiment $(4000 \mu \mathrm{g} / \mathrm{mL})$. The DPPH radical scavenging efficiency was calculated as the inhibition percentage and was determined by using Eq. 2 .

DPPH radical scavenging $(\%)=(($ Blank AB - Sample AB $) /$ Blank AB $) \times 100$

\section{Results and discussion}

\subsection{Morphological analysis of nanofibers}

Characteristically, long chain structure of polymeric carriers and their concentrated solutions ensures the sustainability of electrospinning jet during the process due to the entanglements and overlapping between the polymer chains; thereby bead-free nanofibers are able to be obtained without the breaking of jet (Ramakrishna, Fujihara, Teo, Lim, \& Ma, 2005). Nevertheless, CD molecules can self-assemble and form aggregates via intermolecular hydrogen bonding in their concentrated solutions and as we also reported in pioneer studies, such aggregates in the highly concentrated solutions of CD and their CD-IC makes it possible to perform electrospinning without the need of fiber forming polymeric matrix by ensuring the stabilization of electrospinning jet (Celebioglu \& Uyar, 2010, 2011, 2012).

In this study, three different kinds of modified CD (HP $\beta C D, H P \gamma C D$ and $M(C D$ ) were used separately for the molecular encapsulation of thymol. First, CD-IC of thymol with each CD type (HP $\beta C D, H P \gamma C D$ and $\mathrm{M} \beta C D$ ) was prepared as 1:1 $\mathrm{M}$ ratio of $\mathrm{CD}$ :Thymol in aqueous solution having highly concentrated $\mathrm{CD}$ content $(160 \%, \mathrm{w} / \mathrm{v})$, then, these Thymol/CD-IC aqueous solutions were transformed into solid-state nanofibrous webs (Thymol/CD-IC NF) by polymer-free electrospinning in which no additional fiber forming polymeric matrix was needed (Fig. 1). The electrospun Thymol/CD-IC NF samples (Thymol/HPßCDIC NF, Thymol/HP $\gamma$ CD-IC NF and Thymol/M $\beta C D-I C$ NF) were composed of only CD and thymol, even so, these polymer-free Thymol/CDIC NF nanofibrous webs have shown some mechanical strength along with flexibility and self-standing features (Fig. 2). The viscosity and conductivity of pristine CD, Thymol/CD-IC solutions, and the average fiber diameter (AFD) with diameter range values of nanofibers are shown in Table 1. The morphology of the pure CD NF (Fig. S1) and Thymol/CD-IC NF (Fig. 2) was studied by SEM imaging. As displayed in SEM images, we successfully produced bead-free and uniform nanofibers from all three CD and Thymol/CD-IC systems under the optimized electrospinning conditions/parameters. While the pristine HP $\beta C D$, $\mathrm{HP} \gamma \mathrm{CD}$ and $\mathrm{M} \beta \mathrm{CD} \mathrm{NF}$ were obtained with $1075 \pm 500 \mathrm{~nm}$, $1500 \pm 680 \mathrm{~nm}$ and $135 \pm 85 \mathrm{~nm}$ of AFD, respectively; the AFD was $1180 \pm 305 \mathrm{~nm}$ for Thymol/HPßCD-IC NF, $1430 \pm 490 \mathrm{~nm}$ for Thymol/HP $\gamma$ CD-IC NF and $900 \pm 330 \mathrm{~nm}$ for Thymol/MßCD-IC NF (Table 1). The variation in AFD for different samples is originated from the different solution properties such as different viscosity and 


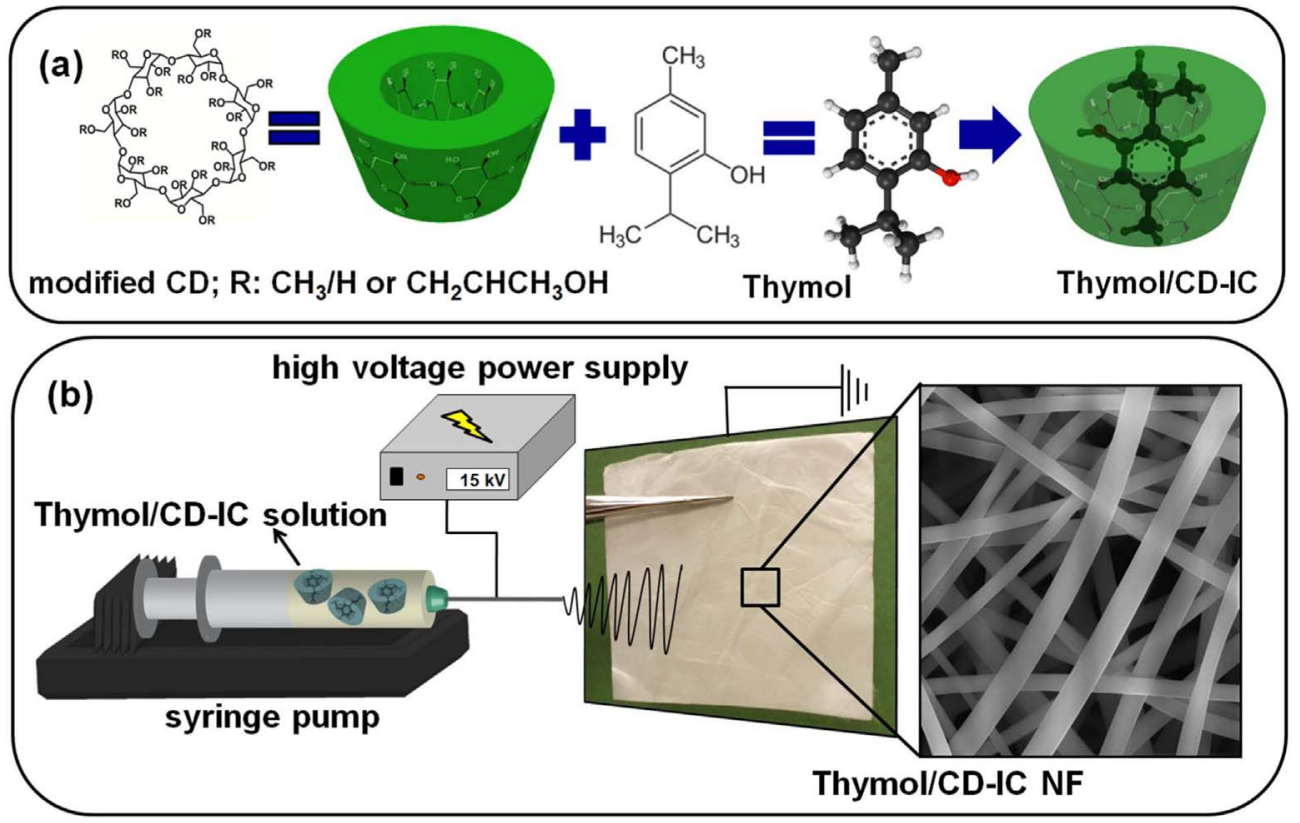

Fig. 1. (a) Chemical structure of modified $C D$ Thymol and schematic representation of IC formation between CD and Thymol. (b) Schematic representation of the electrospinning of $\mathrm{CD}-\mathrm{IC}$ $\mathrm{NF}$

conductivity values. When we compare the AFD of pristine CD NF with each other, it is obvious that the lower viscosity and the quite higher conductivity of $\mathrm{M} \beta \mathrm{CD}$ solution lead to higher stretching and significantly thinner fiber formation compared to other CD NF (HP $\beta C D$ and $\mathrm{HP} \gamma \mathrm{CD}$ ) systems during electrospinning (Celebioglu \& Uyar, 2010, 2011, 2012, Celebioglu, Umu, Tekinay, \& Uyar, 2014; Uyar \& Besenbacher, 2008). In case of Thymol/CD-IC systems, the slightly higher viscosity and the lower conductivity of Thymol/HP $\gamma$ CD-IC solution results in less stretching and so thicker fiber formation compared to other two Thymol/CD-IC systems (Thymol/HPßCD-IC and Thymol/ $\mathrm{M} \beta \mathrm{CD}-\mathrm{IC}$ ). Additionally, the AFD values of pure HP $\beta \mathrm{CD}$ NF and $\mathrm{HP} \gamma \mathrm{CD}$ NF were close to Thymol/HP $\beta C D-I C$ NF and Thymol/HP $\gamma$ CD-IC NF (Table 1). However, the AFD of Thymol/M $\beta C D-I C ~ N F(900 \pm 330 \mathrm{~nm})$ was much thicker compared to pure M $\beta C D$ NF $(135 \pm 85 \mathrm{~nm})$ due to the less stretching of the jet during electrospinning which is because of the low solution conductivity value of Thymol/M $\beta C D-I C$ solution $\left(11.84 \mu \mathrm{S} \mathrm{cm}^{-1}\right)$ compared to pure $\mathrm{M} \beta C D$ solution $\left(978 \mu \mathrm{S} \mathrm{cm}{ }^{-1}\right)$.
Table 1

Properties of the electrospinning solutions and the resulting nanofibers.

\begin{tabular}{|c|c|c|c|c|}
\hline Solutions* & $\begin{array}{l}\text { Viscosity } \\
\text { (Pa.s) }\end{array}$ & $\begin{array}{l}\text { Conductivity } \\
\left(\mu \mathrm{cm}^{-1}\right)\end{array}$ & $\begin{array}{l}\text { Average fiber } \\
\text { diameter (nm) }\end{array}$ & $\begin{array}{l}\text { Fiber } \\
\text { diameter } \\
\text { range }(\mathrm{nm})\end{array}$ \\
\hline HP $\beta C D$ & 0.972 & 17.35 & $1075 \pm 500$ & $160-2700$ \\
\hline $\mathrm{HP} \gamma \mathrm{CD}$ & 1.001 & 6.78 & $1500 \pm 680$ & $485-3200$ \\
\hline $\mathrm{M} \beta \mathrm{CD}$ & 0.650 & 978.00 & $135 \pm 85$ & $40-490$ \\
\hline Thymol/HP $\beta C D-I C$ & 0.634 & 14.06 & $1180 \pm 305$ & $540-1840$ \\
\hline Thymol/HP $\gamma$ CD-IC & 0.671 & 6.91 & $1430 \pm 490$ & $760-2540$ \\
\hline Thymol/MßCD-IC & 0.641 & 11.84 & $900 \pm 330$ & 300-1990 \\
\hline
\end{tabular}

* Solutions were prepared by using $160 \%$ (w/v, with respect to solution) concentrated CD systems.

\subsection{The molar ratio of thymol/CD-IC}

The initial molar ratio of CD:Thymol was adjusted to $1: 1$ for each Thymol/CD-IC system before electrospinning. After the electrospinning, the ultimate molar ratio of CD:Thymol in Thymol/CD-IC NF samples were slightly lower compared to initial amount because of the volatility
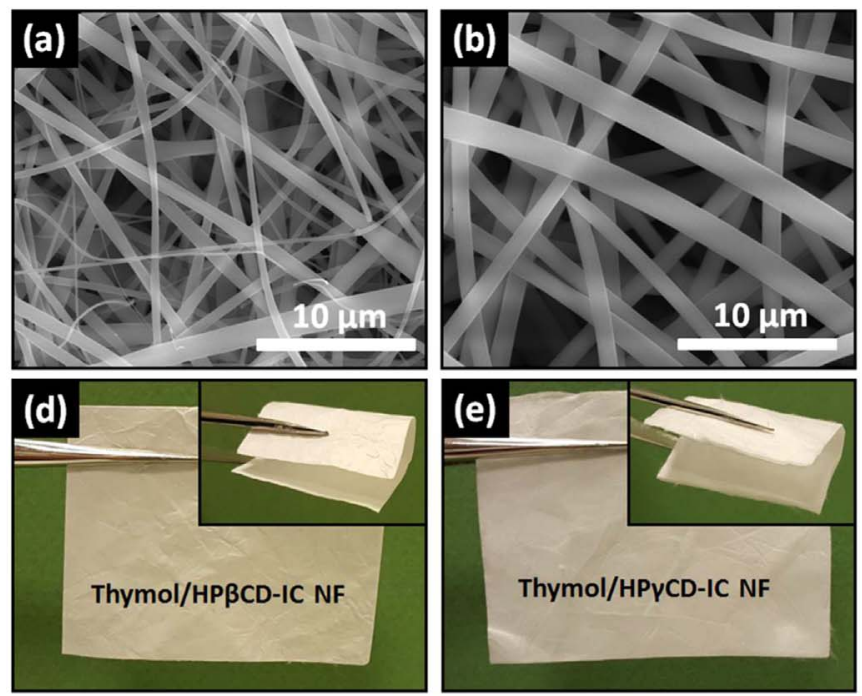

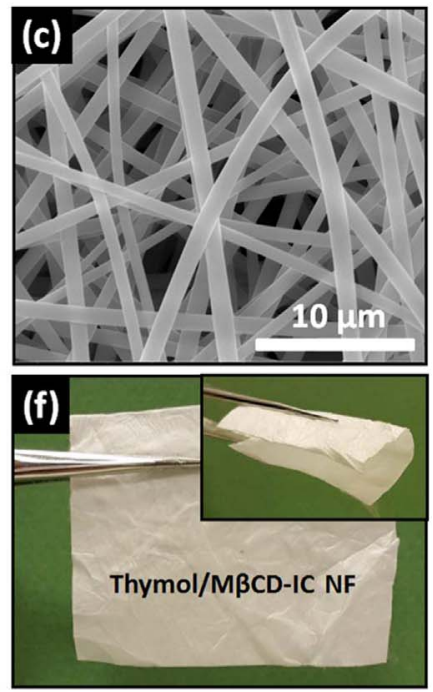

Fig. 2. Representative SEM images and the photographs of electrospun (a-d) Thymol/HP $\beta C D-I C$ NF, (b-e) Thymol/HP $\gamma$ CD-IC NF, (c-f) Thymol/ MBCD-IC NF. 

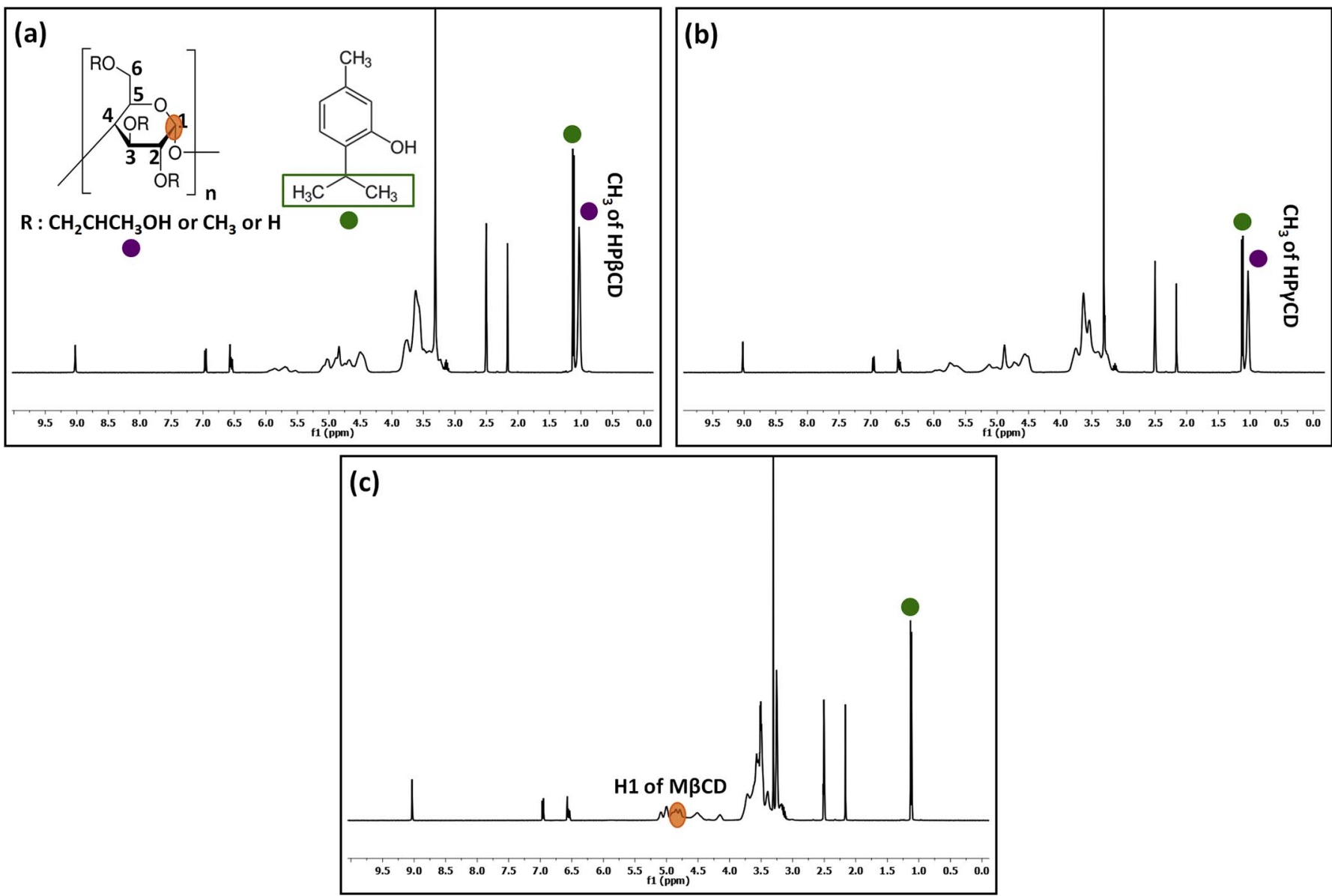

Fig. 3. ${ }^{1} \mathrm{H}$-NMR spectra of (a) Thymol/HP $\beta C D-I C$ NF, (b) Thymol/HP $\gamma$ CD-IC NF and (c) Thymol/M $\beta C D-I C$ NF dissolved in d6-DMSO.

Table 2

${ }^{1} \mathrm{H}$ NMR and TGA calculations indicating the Thymol amount in CD-IC nanofibers in terms of molar ratio (CD:Thymol)/\% (w/ w) comparatively with their initial values.

\begin{tabular}{|c|c|c|c|}
\hline \multirow[t]{2}{*}{ Samples } & Initial amount & ${ }^{1} \mathrm{H}$ NMR results & TGA results \\
\hline & $\begin{array}{l}\text { CD:Thymol; } \\
\text { (molar ratio - \%;w/w*) }\end{array}$ & $\begin{array}{l}\text { CD:Thymol; } \\
\text { (molar ratio - \%;w/w*) }\end{array}$ & $\begin{array}{l}\text { CD:Thymol; } \\
\left(\text { molar ratio }-\% ; \mathrm{w} / \mathrm{w}^{*}\right)\end{array}$ \\
\hline Thymol/HP $\beta C D-I C ~ N F$ & $1.00: 1.00-9.5$ & $1.00: 0.88-8.6$ & $1.00: 0.82-7.8$ \\
\hline Thymol/HP $\gamma$ CD-IC-NF & $1.00: 1.00-8.7$ & $1.00: 1.00-8.7$ & $1.00: 0.88-7.7$ \\
\hline Thymol/MßCD-IC NF & $1.00: 1.00-10.2$ & $1.00: 1.00-10.2$ & $1.00: 0.91-9.5$ \\
\hline
\end{tabular}

${ }^{*}$ For the amount of active agent calculated in terms of $\%, \mathrm{w} / \mathrm{w}$ is respect to total sample amount.

of thymol. The qualitative analysis of thymol in Thymol/CD-IC NF was performed by ${ }^{1} \mathrm{H}$-NMR after electrospinning process, hence the molar ratio between $\mathrm{CD}(\mathrm{HP} \beta \mathrm{CD}, \mathrm{HP} \gamma \mathrm{CD}$ and $\mathrm{M} \beta \mathrm{CD})$ and thymol in Thymol/ CD-IC NF was calculated by integrating the characteristic peaks belonging to $\mathrm{HP} \beta C D \quad(1.00 \mathrm{ppm}), \quad \mathrm{HP} \gamma \mathrm{CD} \quad(1.00 \mathrm{ppm}), \quad \mathrm{M} \beta \mathrm{CD}$ (4.50-5.00 ppm) and thymol (1.10 ppm) (Fig. 3). Pleasingly, the molar ratio of CD:Thymol in Thymol/CD-IC NF samples was not so different from each other and it was very close to the initial value (CD:Thymol; 1:1) (Table 2). Such that, the molar ratio of CD:Thymol was determined as $\sim 1.00: 0.88, \sim 1.00: 1.00$, and $\sim 1.00: 1.00$ for Thymol/HP $\beta C D-I C-N F$, Thymol/HP $\gamma$ CD-IC-NF and Thymol/M $\beta C D-I C-$ $\mathrm{NF}$, respectively. As it is seen, the major amount of thymol was preserved in Thymol/CD-IC NF and only $12 \%$ of thymol was lost in the case of Thymol/HPßCD-IC NF showing that the choice of CD type is important as we also concluded in our previous studies (Aytac et al., 2016a, 2016b; Aytac et al., 2017; Celebioglu et al., 2014; Celebioglu et al., 2016; Celebioglu \& Uyar, 2011, 2017).

\subsection{Thermal analysis of nanofibers}

The thermal stability of thymol in Thymol/CD-IC NF samples was examined by TGA. Fig. 4 indicates the comparative representation of TGA thermograms of pure CD NF, pure thymol and Thymol/CD-IC NF samples. As it is observed in Fig. 4a, pure HPßCD NF, M $\beta C D$ NF and $\mathrm{HP} \gamma \mathrm{CD}$ NF displayed two weight losses below $100{ }^{\circ} \mathrm{C}$ and above $300{ }^{\circ} \mathrm{C}$ corresponding to the water loss and main thermal degradation of $\mathrm{CD}$, respectively. Pure thymol compound starts to evaporate at $50{ }^{\circ} \mathrm{C}$ and completely evaporated at around $140{ }^{\circ} \mathrm{C}$ (Fig. 4b). On the other hand, Thymol/CD-IC NF thermograms have three stages of weight loss which correspond to the water evaporation (below $100{ }^{\circ} \mathrm{C}$ ), thymol evaporation and main degradation of $\mathrm{CD}$ (above $300{ }^{\circ} \mathrm{C}$ ), respectively. In case of Thymol/HP $\beta$ CD-IC NF and Thymol/HP $\gamma$ CD-IC NF, the evaporation of thymol occurred in the range of $85-255^{\circ} \mathrm{C}$ and $100-265^{\circ} \mathrm{C}$, respectively. This significant thermal shift of thymol occurred in Thymol/CDIC NF is an appreciable indicator for inclusion complexation between 

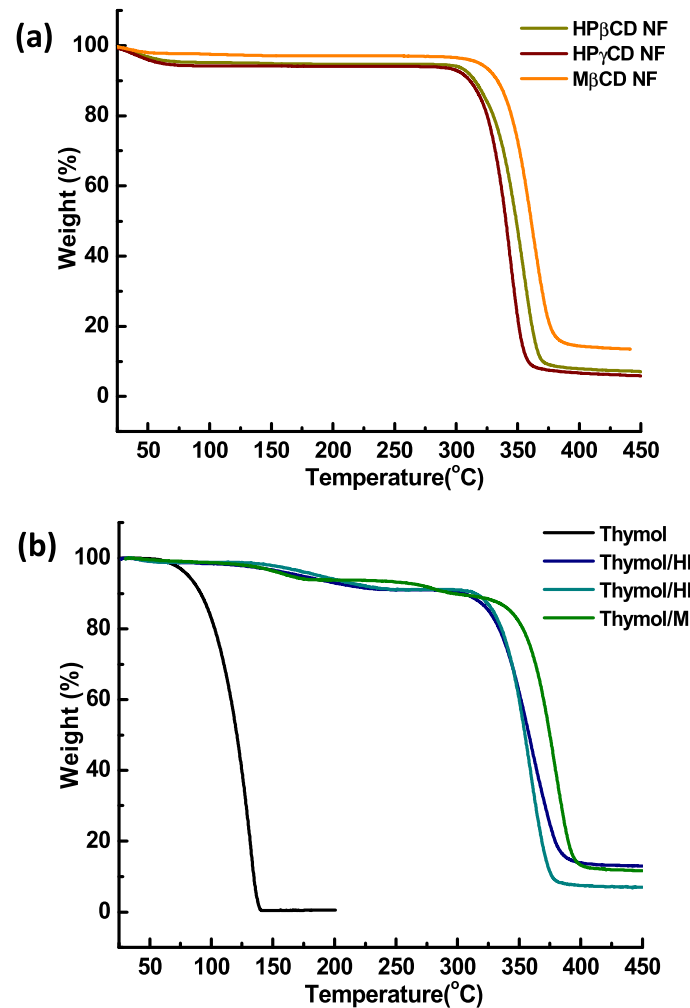
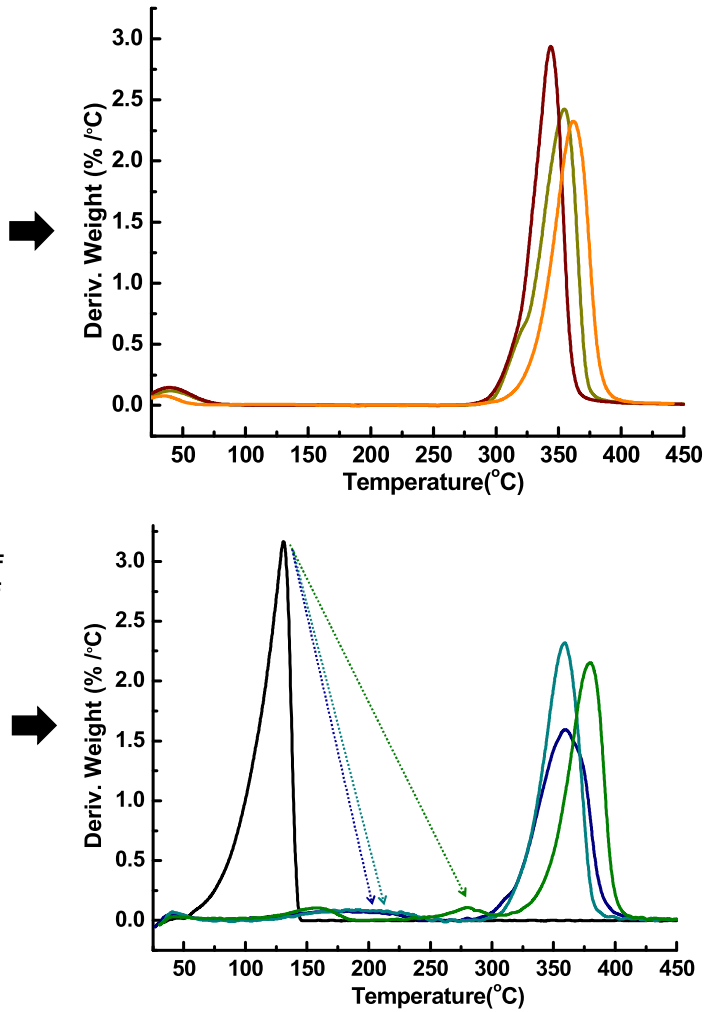

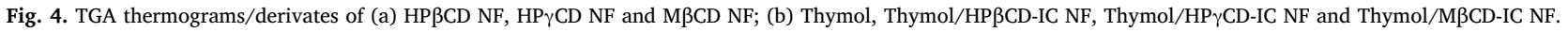

host $\mathrm{CD}(\mathrm{HP} \beta \mathrm{CD}$ and $\mathrm{HP} \gamma \mathrm{CD})$ and guest thymol. Thymol/M $\beta \mathrm{CD}-\mathrm{IC}$ NF depicted two-step weight loss as $90-185^{\circ} \mathrm{C}$ and $225-310{ }^{\circ} \mathrm{C}$ for thymol evaporation. This may be an evidence of two types of complex interaction between $\mathrm{M} \beta \mathrm{CD}$ and thymol contrarily to other two $\mathrm{CD}$ types (HP $\beta C D$ and $H P \gamma C D$ ). Even, the second complexation type might generate with a much stronger manner, as the thermal evaporation of complexed thymol was completed at much higher temperature compared to HP $\beta C D$ and $H P \gamma C D$ systems (Fig.4b). The potential apolar interaction between methyl groups of $\mathrm{M} \beta \mathrm{CD}$ and thymol might promote the complexation strength that could explain the higher thermal evaporation of thymol in the case of Thymol/MBCD-IC NF (Fig. 4b) (Celebioglu et al., 2016).

The replacement of water molecules by active compound in CD cavities causes decrease at the water content of $\mathrm{CD}$ and this is also another indication revealing the inclusion complex formation. Here, the water content of $4.8 \%-5.8 \%$ (observed up to $100{ }^{\circ} \mathrm{C}$ ) for pure CD NF samples (Fig. 4a) was decreased to $0.9-1.4 \%$ range for Thymol/CD-IC $\mathrm{NF}$ samples which further proves the inclusion complexation state between thymol and CD for all three of the Thymol/CD-IC NF samples. TGA measurements also enabled the calculation of thymol amount in Thymol/CD-IC NF (Table 2) and the weight \% of thymol in Thymol/ HP $\beta C D-I C$ NF, Thymol/HP $\gamma$ CD-IC NF and Thymol/M $\beta C D-I C$ NF was found as $7.8 \%, 7.7 \%$ and $9.5 \%(\mathrm{w} / \mathrm{w}$, according to total sample amount), respectively. This revealed that the significant amount of thymol $(\sim 82 \%, 88 \%$ and $91 \%$ for Thymol/HPßCD-IC NF, Thymol/ HP $\gamma$ CD-IC NF and Thymol/M $\beta$ CD-IC NF, respectively) was preserved from evaporation in Thymol/CD-IC NF during the electrospinning processes and storage of the samples. The calculated $\%(w / w)$ values of thymol from the TGA thermograms were also converted in terms of molar ratio (Table 2). The values are not exactly the same with the results derived from ${ }^{1} \mathrm{H}-\mathrm{NMR}$, however, they were comparable with each other. Finally, if we consider the ${ }^{1} \mathrm{H}-\mathrm{NMR}$ and TGA results from the point of different $\mathrm{CD}$ types, it seems that there is slightly less interaction between $\mathrm{HP} \beta \mathrm{CD}$ cavity and Thymol when compared to $\mathrm{HP} \gamma \mathrm{CD}$ and M $\beta \mathrm{CD}$ in Thymol/CD-IC NF samples. When the initial and final molar ratio (CD:Thymol; calculated from both ${ }^{1} \mathrm{H}-\mathrm{NMR}$ and TGA) of Thymol/CD-IC NF was compared, there was slightly more loss of thymol from Thymol/HP $\beta C D-I C$ NF compared to Thymol/HP $\gamma$ CD-IC NF and Thymol/M $\beta C D-I C$ NF. This indicates the slightly lower encapsulation efficiency of thymol in Thymol/HPßCD-IC NF and so the less stable complexation which leads to higher loss of thymol during the electrospinning process and/or storage. In our previous study, we have observed that thymol could not be preserved at all in electrospun zein nanofibers without CD-IC (Aytac, Ipek, Durgun, Tekinay, \& Uyar, 2017). However, highly volatile thymol was effectively protected in Thymol/CD-IC NF samples since the CD-IC nanofiber matrix could preserve much higher thymol content compared to mere polymeric nanofiber matrix.

\subsection{Structural characterization of nanofibers}

Here, FTIR and XRD analyses were performed to confirm the inclusion complexation between CD molecules and thymol. FTIR spectra of the pristine $\mathrm{CD} \mathrm{NF}$, pure thymol, Thymol/CD-IC NF are displayed in Fig. 5. The FTIR spectrum of thymol has characteristic peaks existing in the $1250-1750 \mathrm{~cm}^{-1}$ region of the spectrum which are assigned to $\mathrm{C}=\mathrm{C}$ stretching, $-\mathrm{OH}$ bending and $\mathrm{C}-\mathrm{O}$ stretching of phenolic groups of thymol (Fig. 5b) (Rukmani \& Mahalingam, 2012). On the other hand, the characteristic peaks of CD NF and Thymol/CD-IC NF were observed at around 1020-1070 (coupled $\mathrm{C}-\mathrm{C} / \mathrm{C}-\mathrm{O}$ stretching vibrations), $1150 \mathrm{~cm}^{-1}$ (anti-symmetric stretching vibration of the $\mathrm{C}-\mathrm{O}-\mathrm{C}$ glycosidic bridge), $1638 \mathrm{~cm}^{-1}\left(\mathrm{H}-\mathrm{OH}\right.$ bending), $2925 \mathrm{~cm}^{-1}(\mathrm{C}-\mathrm{H}$ stretching) and $3401 \mathrm{~cm}^{-1}$ (O-H stretching) (Celebioglu et al., 2016) (Fig. 5a-b). Although the overlapping of the characteristic peaks of CD and thymol complicates the analyses of the data, the characteristic peak of thymol at $1622 \mathrm{~cm}^{-1}$ and $1286 \mathrm{~cm}^{-1}$ originates from the $\mathrm{C}=\mathrm{C}$ stretching and $\mathrm{C}-\mathrm{O}$ stretching of phenolic group, respectively were recorded for all Thymol/CD-IC NF. The inclusion complexation can induce some FTIR peak shifts as a result of certain interaction between host and guest molecules (Celebioglu et al., 2016). The shift of 

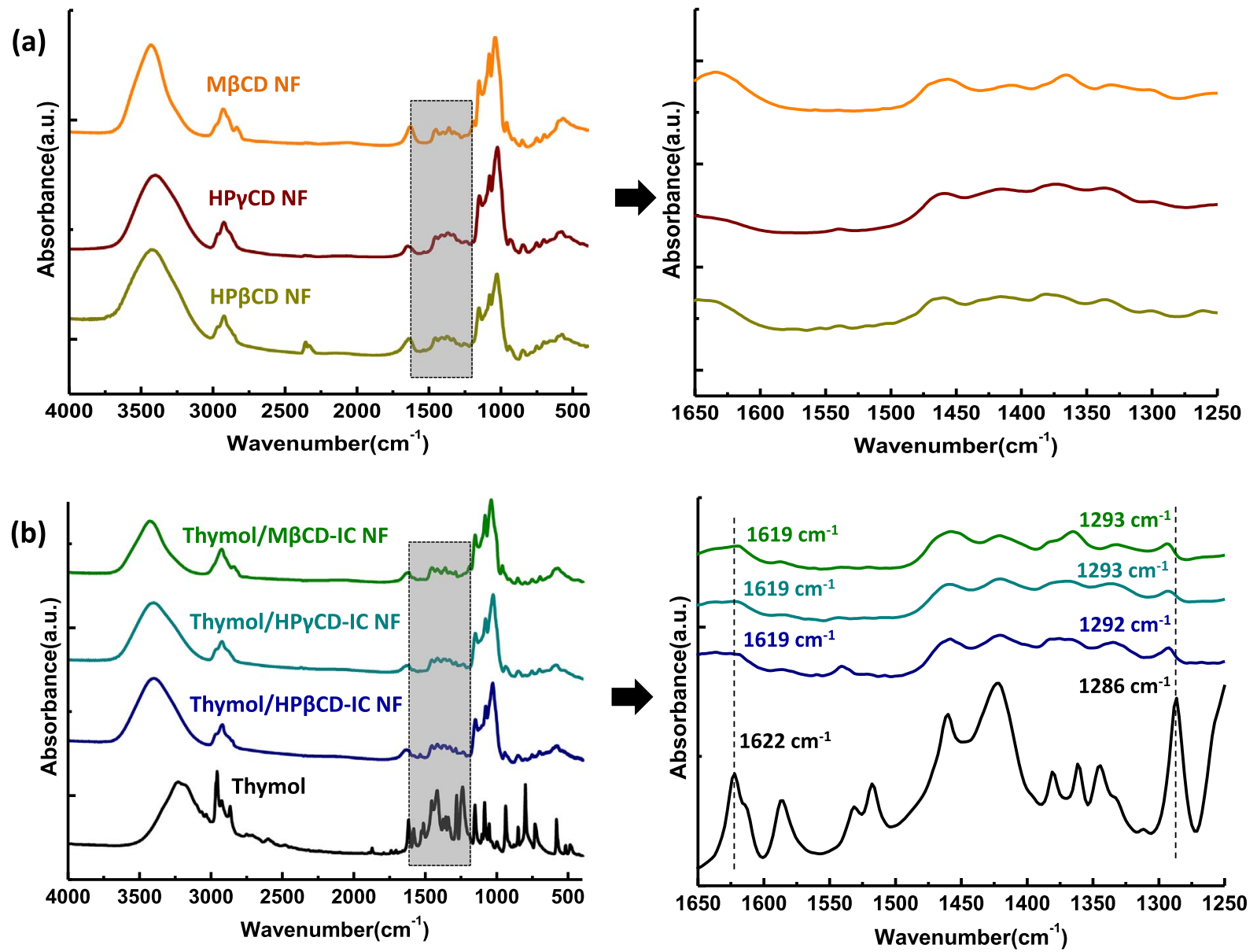

Fig. 5. FTIR spectra of (a) HP $\beta C D$ NF, HP $\gamma$ CD NF and M $\beta C D$ NF; (b) Thymol, Thymol/HP $\beta C D-I C$ NF, Thymol/HP $\gamma$ CD-IC NF and Thymol/M $\beta C D-I C$ NF.

characteristic peaks of thymol from $1622 \mathrm{~cm}^{-1}$ to $1619 \mathrm{~cm}^{-1}$ and $1286 \mathrm{~cm}^{-1}$ to $1293 \mathrm{~cm}^{-1}$ further suggested the inclusion complexation state between thymol and CD molecules in Thymol/CD-IC NF samples.

Thymol is a crystalline material having a distinct diffraction peaks centered at $2 \theta=8,19$ and $26^{\circ}$ (Fig. 6). The HP $\beta C D, H P \gamma C D$ and $M \beta C D$ are known with their amorphous structure (Celebioglu et al., 2016). XRD graphs indicate that the pure CD NF have amorphous pattern (Fig. 6a) and Thymol/CD-IC NF have also represent amorphous structure (Fig. 6b) just like pure CD types without displaying any specific thymol diffraction peak. Since, thymol molecules were separated from each other by the inclusion in $\mathrm{CD}$ cavities and that hinders the formation of thymol crystals. This result strongly suggested the inclusion complexation between thymol and CD molecules (HP $\beta C D, H P \gamma C D$ and $\mathrm{M} \beta C D$ ) for Thymol/CD-IC NF samples (Fig. 6b).

\subsection{Phase solubility and water solubility studies}

Thymol is a widely used compound in food products but it has a poor water solubility. Here, the solubility enhancement of thymol was depicted by phase solubility tests as a function of increasing CD concentration. The phase solubility diagrams can be formed in different types depending on stoichiometric variations and here the phase solubility diagrams of Thymol/CD-IC displayed $A_{L}$ type pattern suggesting linear increment in the solubility of thymol with the increasing $C D$ concentration (Higuchi \& Connors, 1965). The $A_{L}$ diagram also suggested the 1:1 complex formation tendency of active agent with $C D$ molecules (Fig. 7). As it is seen from the diagrams, $\mathrm{HP} \beta \mathrm{CD}$ and $\mathrm{M} \beta \mathrm{CD}$ afford relatively higher increase at the solubility of thymol compared to HP $\gamma$ CD by a linear manner for the studied CD concentration range. This is most probably originated from the bigger cavity size of $\mathrm{HP} \gamma \mathrm{CD}$ which is not as effective as $\mathrm{HP} \beta \mathrm{CD}$ and $\mathrm{M} \beta \mathrm{CD}$ for stabilizing the interaction with thymol in the dynamic environment of water. Besides, the stability constant $\left(\mathrm{K}_{\mathrm{s}}\right)$ values of CD-IC were determined according to Eq. 1 by using phase solubility diagrams. $\mathrm{K}_{\mathrm{s}}$ values of CD-IC were calculated as $430 \mathrm{M}^{-1}, 163 \mathrm{M}^{-1}$ and $477 \mathrm{M}^{-1}$ for Thymol/HPßCD-IC, Thymol/ HP $\gamma$ CD-IC and Thymol/M $\beta C D-I C$, respectively. These results are also correlated with the previously reported study by Tao et al., in which the $\mathrm{K}_{\mathrm{s}}$ value was determined as $457 \mathrm{M}^{-1}$ for Thymol/ $\beta \mathrm{CD}$ at RT (Tao, Hill, Peng, \& Gomes, 2014). In principle, the value of $\mathrm{K}_{\mathrm{s}}$ indicates the binding strength between guest molecules and CD (Ciobanu et al., 2013; Marques, 2010) and based on these results, it can be concluded that $\mathrm{HP} \beta C D$ and $M \beta C D$ can form more stable complexes with thymol compared to $\mathrm{HP} \gamma \mathrm{CD}$ in the dynamic water environment. The disintegration test of Thymol/CD-IC NF was also performed in water to prove the water-solubility enhancement of thymol in Thymol/CD-IC NF. As it is seen in Fig. 8, pure thymol crystals are still obvious in water even after stirring overnight; however Thymol/CD-IC NF samples were readily disintegrated in water without any undissolved thymol residual due to the inclusion complexation (Movie S1). Additionally, the comparative solubility of Thymol/CD-IC powder indicated that, CD-IC NF tend to dissolve more readily in water compared to powder form of samples (Movie S2) owing to the high surface area and nanoscale porosity of nanofibrous webs contributing to fast-dissolving property by enhancing the penetration and interaction of water within the Thymol/ CD-IC NF samples.

\subsection{Antioxidant activity}

Essential oils (EO) having antioxidant properties are extraction product of natural plants and they are commonly used in food, 

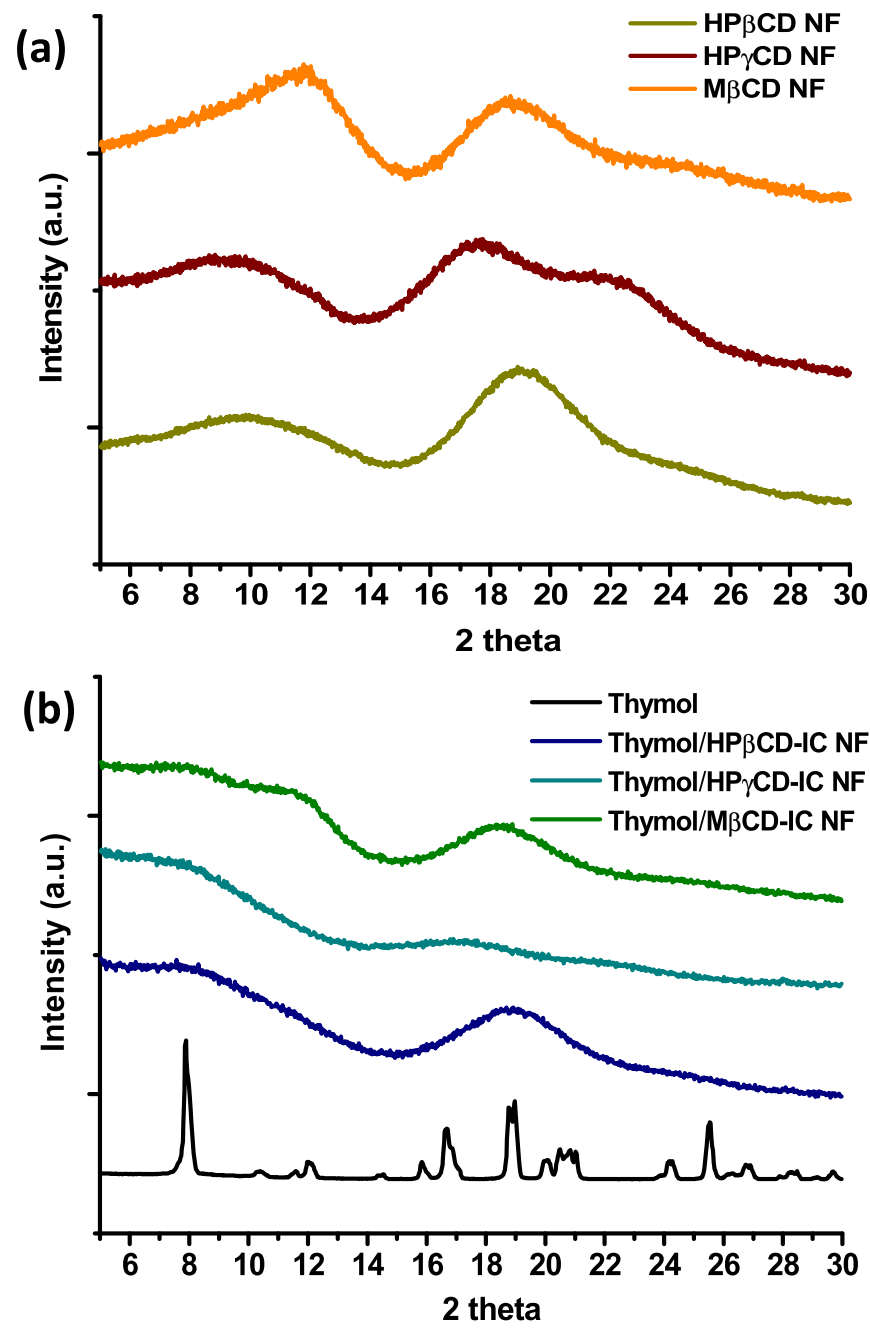

Fig. 6. XRD patterns of (a) HP $\beta C D$ NF, HP $\gamma C D$ NF and M $\beta C D$ NF; (b) Thymol, Thymol/ HP $\beta C D-I C$ NF, Thymol/HP $\gamma$ CD-IC NF and Thymol/M $\beta C D-I C$ NF. pharmaceutical and cosmetic industries. The volatile compounds such as; terpenes, terpenoids, phenolic aromatic and aliphatic compounds are the main components which ensure the high antioxidant potential of EO (Bakkali et al., 2008). Due to its phenolic structure, thymol is one of the most effective natural antioxidant found in EO. This active compound can inhibit lipidic peroxidation in biological systems and biomolecules which are induced by reactive oxygen species (ROS) and can cause diseases/aging or spoiling of foods (Bakkali et al., 2008; Li et al., 2012; Mastelic et al., 2008). Among various techniques, 2,2-diphenyl-1-picrylhydrazyl (DPPH) is a reasonable one when radical scavenging abilities of active agents are investigated at room temperature (Antolovich, Prenzler, Patsalides, McDonald, \& Robards, 2002; Sharma \& Bhat, 2009). By this technique, hydrogen donor; free radical scavenging antioxidant reduce the DPPH molecules and it cause the diminishing of the strongest absorption $(517 \mathrm{~nm}$ ) band and the purple color of solution turns yellowish upon completion of reaction (Fig. 9a). Here, the antioxidant property of Thymol/CD-IC NF was firstly evaluated by the concentration dependent tests, dissolving samples in the concentration range of 50-4000 $\mu \mathrm{g} / \mathrm{mL}$. For this, the clear Thymol/CDIC NF solutions were obtained having different concentrations and pure thymol was prepared according to the initial thymol content $(10 \% \mathrm{w} /$ $\mathrm{w}$, with respect to the total sample amount) used in electrospinning solutions and the highest Thymol/CD-IC NF amount $(4000 \mu \mathrm{g} / \mathrm{mL})$. As known, pure thymol has quite limited solubility in water and this makes it difficult to prepare clear and homogenous thymol solution, therefore the undissolved thymol was filtered before the antioxidant experiment. After $30 \mathrm{~min}$. of incubation, UV-Vis measurements of all samples (Thymol/CD-IC NF and pure thymol) were carried out and Fig. 9a demonstrates the concentration dependent \%DPPH radical scavenging graphs of Thymol/CD-IC NF and their ultimate solutions photographs. As an expected result, the radical scavenging efficiency of Thymol/CDIC NF increased by the increasing sample concentrations (Fig. 9a). Here, the inhibition efficiencies reached to $95 \%, 93 \%$ and $95 \%$ for Thymol/ HP $\beta C D-I C$ NF, Thymol/HP $\gamma$ CD-IC NF and Thymol/M $\beta C D-I C$ NF, respectively by using $4000 \mu \mathrm{g} / \mathrm{mL}$ sample concentration (Fig. 9b). Contrastingly, pure thymol system indicated only $25 \%$ antioxidant activity under the same condition (Fig. 9b). The underlying reason of the improved antioxidant efficiency of thymol is derived from encapsulation of this active compound into $\mathrm{CD}$ cavities which provide efficient (a)

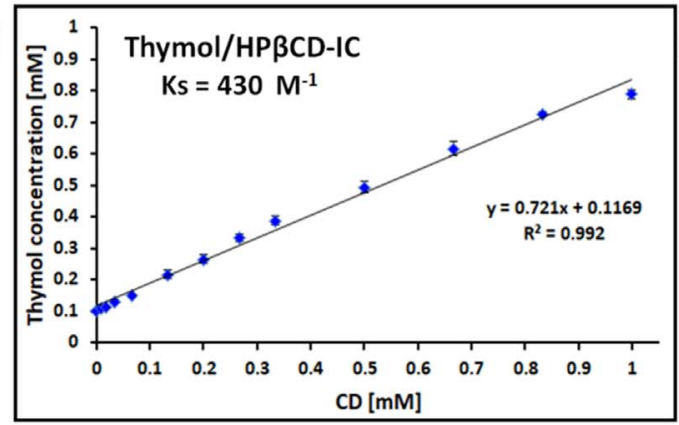

(b)

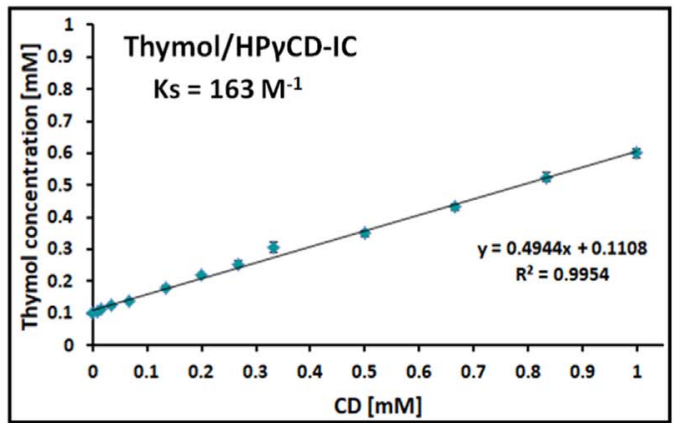

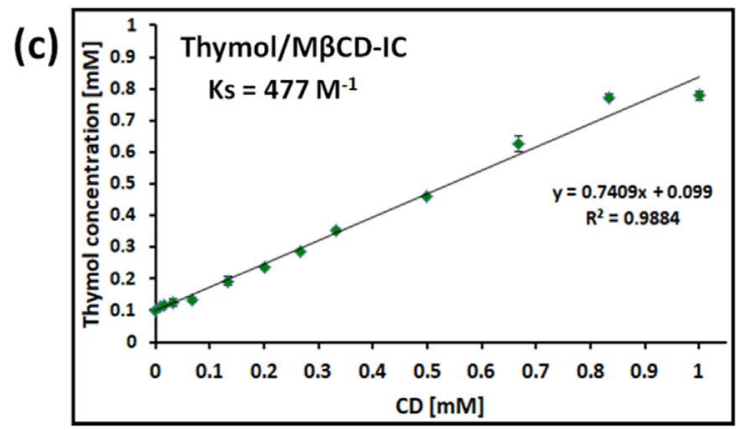

Fig. 7. Phase solubility diagrams of (a) Thymol/HP $\beta C D-I C$, (b) Thymol/HP $\gamma$ CD-IC and (c) Thymol/M $\beta C D-I C$ systems $(n=3)$. 


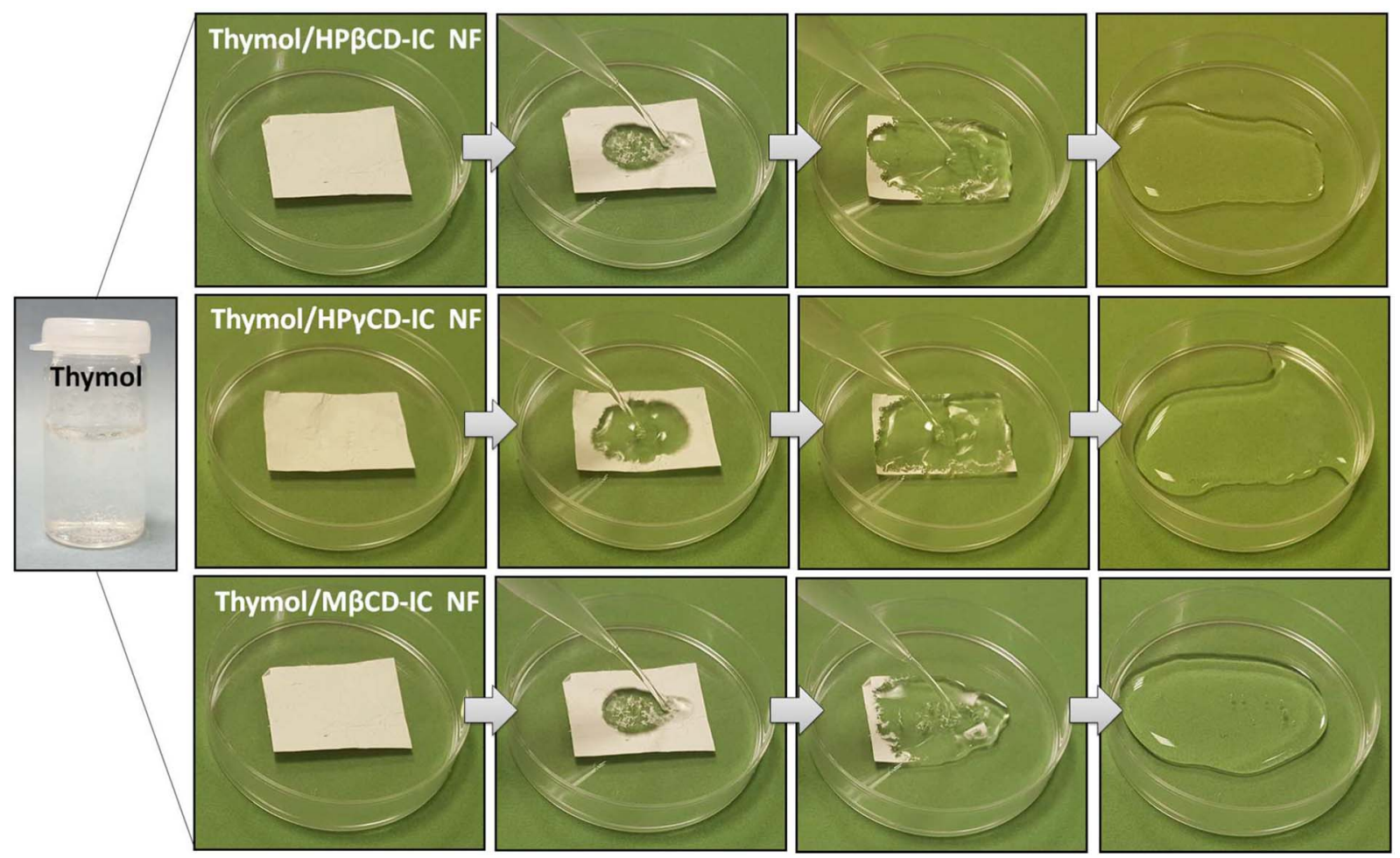

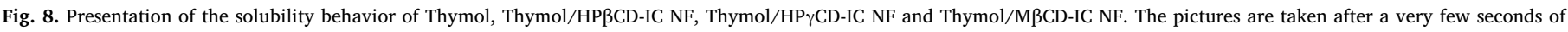
water exposure.
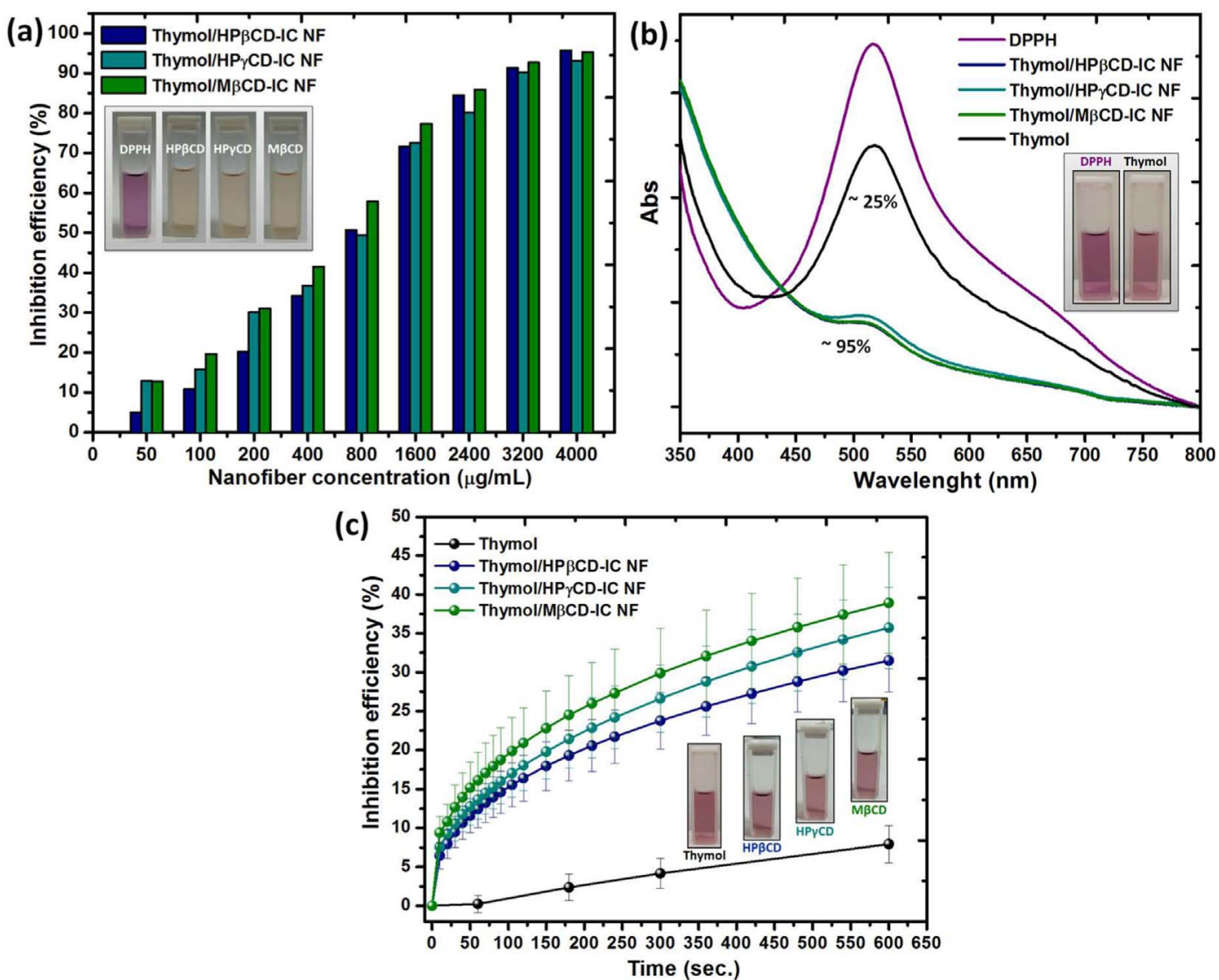

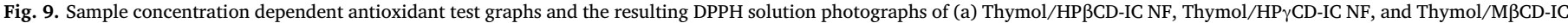

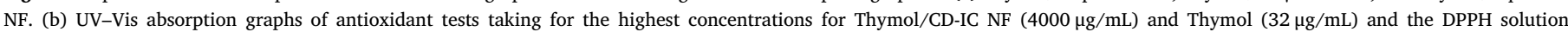

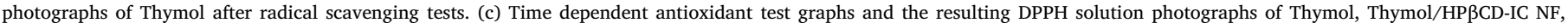
Thymol/HP $\gamma$ CD-IC NF and Thymol/MBCD-IC NF $(n=3)$. 
solubility for them in liquid environment and increase their participation potential for the radical scavenging process (Fig. 7-8). Additionally, concentration dependent results enabled the calculation of $50 \%$ inhibition (IC50) values as; $773 \mu \mathrm{g} / \mathrm{mL}, 834 \mu \mathrm{g} / \mathrm{mL}$ and $476 \mu \mathrm{g} /$ $\mathrm{mL}$ for Thymol/HP $\beta C D-I C$ NF, Thymol/HP $\gamma$ CD-IC NF and Thymol/ MBCD-IC NF, respectively. The obtained IC50 values revealed that, Thymol/M $\beta$ CD-IC NF need the lowest sample amount to display the DPPH radical scavenging activity among other Thymol/CD-IC NF. This remarkable difference is most probably is appeared because of the highest thymol content in Thymol/MBCD-IC NF compared to Thymol/ HP $\beta C D-I C$ NF and Thymol/HP $\gamma$ CD-IC NF samples. Thymol is a highly efficient antioxidant compound, since it has a hydroxyl group which is sterically hindered by a $t$-butyl group (Brand-Williams, Cuvelier, \& Berset, 1995; Yanishlieva, Marinova, Gordon, \& Raneva, 1999). In case of inclusion complexation, the methyl moiety is oriented toward the narrow end of the $\mathrm{CD}$ cavity whereas the isopropyl group points to the wider rim (Mulinacci, Melani, Vincieri, Mazzi, \& Romani, 1996). Because of concerned coordination, there is no restriction originating from complex formation that could hinder $\mathrm{OH}$ group activity and thus the radical scavenging property of thymol (Kfoury et al., 2016).

Here, time dependent radical scavenging tests were carried out to discover the antioxidant performances differences between samples more precisely. The highest sample concentration which was applied for concentration dependent experiments $(4000 \mu \mathrm{g} / \mathrm{mL})$ was used for the time dependent tests. The time dependent DPPH scavenging performances of samples were recorded up to $10 \mathrm{~min}$. At the first glance, the worse antiradical reaction profile of pure thymol attracts the attention compared to Thymol/CD-IC NF in the graphs (Fig. 9c), even the related amount of thymol was used within CD-IC nanofibers. This is originated from the enhanced solubility of thymol, which is acquired by the inclusion complexation with $\mathrm{CD}$, increases the amount of thymol could rank in the scavenging progression. When Thymol/CD-IC NF is evaluated according to CD types, the reaction rate is higher for Thymol/ MßCD-IC NF compared to Thymol/HP $\gamma$ CD-IC NF and it is at the lowest value for Thymol/HP $\beta C D-I C$ NF. This trend was partially supported by the amount of thymol compounds in the CD-IC nanofibers which was calculated in the order of Thymol/M 3 CD-IC NF $(10.2 \%, w / w)>$ Thymol/HP $\gamma$ CD-IC NF $(8.7 \%, w / w)>$ Thymol/HP $\beta$ CD-IC NF $(8.6 \%$, $\mathrm{w} / \mathrm{w}$ ) from ${ }^{1} \mathrm{H}$-NMR measurements. As it is seen, the amount of thymol is almost same for HP $\gamma$ CD-IC NF and HP $\beta C D-I C N F$, so the binding strength variation of $\mathrm{HP} \gamma \mathrm{CD}$ and $\mathrm{HP} \beta C D$ can be effective in this case. Here, the bigger cavity size of $\mathrm{HP} \gamma \mathrm{CD}$ most probably creates more relaxed location for thymol in the liquid environment and this enables faster reduction of DPPH due to hindered effect on the hydroxyl group of thymol molecules. Briefly, the enhanced activity of thymol can be attributed to the inclusion complexation that both provide stabilization and solubility enhancement thereby improved radical scavenging potential of this active compound.

\section{Conclusion}

In this study, the free-standing and morphologically homogenous nanofibrous webs were successfully produced from the inclusion complexes (IC) of modified CD (HP $\beta C D, H P \gamma C D$ and $M \beta C D)$ and volatile essential oil extraction product; thymol, without using any carrier polymeric matrix via electrospinning technique. ${ }^{1} \mathrm{H}-\mathrm{NMR}$ analysis confirmed the existence of thymol in the CD-IC nanofibers and it was also found that very high amount of thymol was protected in the CD-IC nanofibers due to the inclusion complexation with $\mathrm{CD}$. Such that, the preserved amount of thymol in Thymol/HP $\beta$ CD-IC NF, Thymol/HP $\gamma$ CDIC NF and Thymol/M $\beta$ CD-IC NF are $\sim 88 \%, \sim 100 \%$ and $\sim 100 \%$ of initial amount of active agent, respectively. The FTIR and XRD measurements were performed for further structural analysis and these results further confirmed the complex formation between thymol and $\mathrm{CD}$ in Thymol/CD-IC NF nanofibrous web samples. The inclusion complexation between thymol and $\mathrm{CD}$ molecules was also revealed by
TGA measurements indicating the clear shift of thermal evaporation of Thymol (from $140{ }^{\circ} \mathrm{C}$ ) to the much higher temperature (up to $310^{\circ} \mathrm{C}$ ). This is also evidence for the enhanced thermal stability of thymol compounds owing to the inclusion complex formation. The disintegration tests indicated that while Thymol/CD-IC NF were readily dissolved in water, pure thymol was not soluble in water because of its poor solubility. Moreover, Thymol/CD-IC NF samples were more readily disintegrated and dissolved in water when compared to Thymol/CD-IC powder form. Additionally, water-solubility improvement ensured by inclusion complexation was demonstrated by the phase solubility tests for the Thymol/CD-IC aqueous systems. When we compare the Thymol/ CD-IC NF from the point of different CD types, we have observed that $\mathrm{M} \beta \mathrm{CD}$ tends to form more stable inclusion complexes with thymol compared to HP $\beta C D$ and $\mathrm{HP} \gamma \mathrm{CD}$. The antioxidant profile of Thymol/ CD-IC NF was evaluated by DPPH radical scavenging tests and the results revealed that Thymol/CD-IC NF can display more efficient scavenging property compared to its pure state owing to enhanced solubility originating from IC mechanism. To conclude, thymol and their CD-IC were transformed into more applicable free-standing and easily handled nanofibrous forms compared to their powder form along with quite high thymol content with an effective protection after electrospinning process. The ultimate Thymol/CD-IC NF may be an attractive material for food related applications by the synergy of particularly large surface area of nanofiber with non-toxic nature of $\mathrm{CD}$ and inclusion complexation which provides improved water solubility, high temperature stability and enhanced antioxidant property. Additionally, fast-dissolving property of Thymol/CD-IC nanowebs can provide advantage and make this kind of materials attractive especially for food, pharmaceutics and oral-care applications as fast dissolving tablets/ strips.

Supplementary data to this article can be found online at https:// doi.org/10.1016/j.foodres.2017.12.062.

\section{Acknowledgement}

T.U. acknowledges the Scientific and Technological Research Council of Turkey (TUBITAK)-Turkey (Project \#213M185) for funding this research. A.C. and Z. I. Y. thanks to TUBITAK-BIDEB for the PhD scholarship.

\section{Funding}

This work was supported by the Scientific and Technological Research Council of Turkey 498 (TUBITAK)-Turkey (Project \#213M185).

\section{References}

Ali, S. M., Asmat, F., \& Maheshwari, A. (2004). NMR spectroscopy of inclusion complex of D-(-)-chloramphenicol with $\beta$-cyclodextrin in aqueous solution. Il Farmaco, 59(10), 835-838.

Antolovich, M., Prenzler, P. D., Patsalides, E., McDonald, S., \& Robards, K. (2002). Methods for testing antioxidant activity. Analyst, 127, 183-198.

Aytac, Z., Dogan, S. Y., Tekinay, T., \& Uyar, T. (2014). Release and antibacterial activity of allyl isothiocyanate/ $\beta$-cyclodextrin complex encapsulated in electrospun nanofibers. Colloids and Surfaces B: Biointerfaces, 120, 125-131.

Aytac, Z., Ipek, S., Durgun, E., Tekinay, T., \& Uyar, T. (2017). Antibacterial electrospun zein nanofibrous web encapsulating thymol/cyclodextrin-inclusion complex for food packaging. Food Chemistry, 233, 117-124.

Aytac, Z., Keskin, N. O. S., Tekinay, T., \& Uyar, T. (2017). Antioxidant $\alpha$-tocopherol $/ \gamma$ cyclodextrin-inclusion complex encapsulated poly (lactic acid) electrospun nanofibrous web for food packaging. Journal of Applied Polymer Science, 134, 44858.

Aytac, Z., Kusku, S. I., Durgun, E., \& Uyar, T. (2016a). Encapsulation of gallic acid/cyclodextrin inclusion complex in electrospun polylactic acid nanofibers: Release behavior and antioxidant activity of gallic acid. Materials Science and Engineering: C, 63, 231-239.

Aytac, Z., Kusku, S. I., Durgun, E., \& Uyar, T. (2016b). Quercetin/ B-cyclodextrin inclusion complex embedded nanofibres: Slow release and high solubility. Food Chemistry, 197, 864-871.

Aytac, Z., Yildiz, Z. I., Kayaci-Senirmak, F., San Keskin, N. O., Kusku, S. I., Durgun, E., .. Uyar, T. (2016a). Fast-dissolving, prolonged release, and antibacterial cyclodextrin/ 
limonene-inclusion complex nanofibrous webs via polymer-free electrospinning. Journal of Agricultural and Food Chemistry, 64(39), 7325-7334.

Aytac, Z., Yildiz, Z. I., Kayaci-Senirmak, F., San Keskin, N. O., Tekinay, T., \& Uyar, T. (2016b). Electrospinning of polymer-free cyclodextrin/geraniol-inclusion complex nanofibers: Enhanced shelf-life of geraniol with antibacterial and antioxidant properties. RSC Advances, 6(52), 46089-46099.

Aytac, Z., Yildiz, Z. I., Kayaci-Senirmak, F., Tekinay, T., \& Uyar, T. (2017). Electrospinning of cyclodextrin/linalool-inclusion complex nanofibers: Fast-dissolving nanofibrous web with prolonged release and antibacterial activity. Food Chemistry, 231, 192-201.

Bakkali, F., Averbeck, S., Averbeck, D., \& Idaomar, M. (2008). Biological effects of essential oils-A review. Food and Chemical Toxicology, 46(2), 446-475.

Bilia, A. R., Guccione, C., Isacchi, B., Righeschi, C., Firenzuoli, F., \& Bergonzi, M. C. (2014). Essential oils loaded in nanosystems: A developing strategy for a successful therapeutic approach. Evidence-Based Complementary and Alternative Medicine (ID 651593).

Brand-Williams, W., Cuvelier, M. E., \& Berset, C. L. W. T. (1995). Use of a free radical method to evaluate antioxidant activity. LWT-Food science and Technology, 28(1), 25-30.

Cavaliere, S. (Ed.). (2015). Electrospinning for advanced energy and environmental applications. CRC Press.

Celebioglu, A., Kayaci-Senirmak, F., İpek, S., Durgun, E., \& Uyar, T. (2016). Polymer-free nanofibers from vanillin/cyclodextrin inclusion complexes: High thermal stability, enhanced solubility and antioxidant property. Food \& Function, 7(7), 3141-3153.

Celebioglu, A., Umu, O. C., Tekinay, T., \& Uyar, T. (2014). Antibacterial electrospun nanofibers from triclosan/cyclodextrin inclusion complexes. Colloids and Surfaces B: Biointerfaces, 116, 612-619.

Celebioglu, A., \& Uyar, T. (2010). Cyclodextrin nanofibers by electrospinning. Chemical Communications, 46(37), 6903-6905.

Celebioglu, A., \& Uyar, T. (2011). Electrospinning of polymer-free nanofibers from cyclodextrin inclusion complexes. Langmuir, 27, 6218-6226.

Celebioglu, A., \& Uyar, T. (2012). Electrospinning of nanofibers from non-polymeric systems: Polymer-free nanofibers from cyclodextrin derivatives. Nanoscale, 4 , 621-631.

Celebioglu, A., \& Uyar, T. (2017). Antioxidant vitamin E/cyclodextrin inclusion complex electrospun nanofibers: Enhanced water-solubility, prolonged shelf-life, and photostability of vitamin E. Journal of Agriculture and Food Chemistry, 65, 5404-5412.

Ciobanu, A., Landy, D., \& Fourmentin, S. (2013). Complexation efficiency of cyclodextrins for volatile flavor compounds. Food Research International, 53, 110-114.

Del Valle, E. M. (2004). Cyclodextrins and their uses: A review. Process Biochemistry, 39(9), 1033-1046.

Fathi, M., Mozafari, M. R., \& Mohebbi, M. (2012). Nanoencapsulation of food ingredients using lipid based delivery systems. Trends in Food Science \& Technology, 23(1), 13-27.

Higuchi, T. K., \& Connors, A. (1965). Phase-solubility techniques. Advanced Analytical Chemistry of Instrumentation, 4, 117-212.

Kayaci, F., Ertas, Y., \& Uyar, T. (2013). Enhanced thermal stability of eugenol by cyclodextrin inclusion complex encapsulated in electrospun polymeric nanofibers. Journal of Agricultural and Food Chemistry, 61(34), 8156-8165.

Kayaci, F., Sen, H. S., Durgun, E., \& Uyar, T. (2014). Functional electrospun polymeric nanofibers incorporating geraniol-cyclodextrin inclusion complexes: High thermal stability and enhanced durability of geraniol. Food Research International, 62, 424-431.

Kayaci, F., Umu, O. C., Tekinay, T., \& Uyar, T. (2013). Antibacterial electrospun poly (lactic acid) (PLA) nanofibrous webs incorporating triclosan/cyclodextrin inclusion complexes. Journal of Agricultural and Food Chemistry, 61(16), 3901-3908.

Kayaci, F., \& Uyar, T. (2012). Encapsulation of vanillin/cyclodextrin inclusion complex in electrospun polyvinyl alcohol (PVA) nanowebs: Prolonged shelf-life and high temperature stability of vanillin. Food Chemistry, 133(3), 641-649.

Kfoury, M., Landy, D., Ruellan, S., Auezova, L., Greige-Gerges, H., \& Fourmentin, S. (2016). Determination of formation constants and structural characterization of cyclodextrin inclusion complexes with two phenolic isomers: Carvacrol and thymol. The Beilstein Journal of Organic Chemistry, 12, 29-42.
Li, K. K., Yin, S. W., Yang, X. Q., Tang, C. H., \& Wei, Z. H. (2012). Fabrication and characterization of novel antimicrobial films derived from thymol-loaded zein-sodium caseinate (SC) nanoparticles. Journal of Agricultural and Food Chemistry, 60(46), 11592-11600.

Llana-Ruiz-Cabello, M., Pichardo, S., Maisanaba, S., Puerto, M., Prieto, A. I., GutierrezPraena, D., ... Camean, A. M. (2015). In vitro toxicological evaluation of essential oils and their main compounds used in active food packaging: A review. Food and Chemical Toxicology, 81, 9-27.

Marques, H. M. (2010). A review on cyclodextrin encapsulation of essential oils and volatiles. Flavour and Fragrance Journal, 25, 313-326.

Mastelic, J., Jerkovic, I., Blažević, I., Poljak-Blaži, M., Borović, S., Ivančić-Baće, I., ... Müller, N. (2008). Comparative study on the antioxidant and biological activities of carvacrol, thymol, and eugenol derivatives. Journal of Agricultural and Food Chemistry, 56(11), 3989-3996.

Mittal, V., Pérez-Mariá, R., Fabra, M. J., Lagarón, J. M., \& López-Rubio, A. (2012). Use of electrospinning for encapsulation. Wiley.

Moomand, K., \& Lim, L.-T. (2014). Oxidative stability of encapsulated fish oil in electrospun zein fibres. Food Research International, 62, 523-532.

Mulinacci, N., Melani, F., Vincieri, F. F., Mazzi, G., \& Romani, A. (1996). ${ }^{1} \mathrm{H}-\mathrm{NMR}$ NOE and molecular modelling to characterize thymol and carvacrol cyclodextrin complexes. International Journal of Pharmaceutics, 128, 81-88.

Noruzi, M. (2016). Electrospun nanofibres in agriculture and the food industry: A review. Journal of the Science of Food and Agriculture, 96, 4663-4678.

Ramakrishna, S., Fujihara, K., Teo, W., Lim, T., \& Ma, Z. (2005). An introduction to electrospinning and nanofibers. World Scientific Publishing Company.

Rukmani, A., \& Mahalingam, S. (2012). Inclusion of antibacterial agent thymol on $\beta$ cyclodextrin-grafted organic cotton. Journal of Industrial Textile, 42, 132-144.

Sharma, O. M., \& Bhat, T. K. (2009). DPPH antioxidant assay revisited. Food Chemistry, 113, 1202-1205.

Szejtli, J. (1998). Introduction and general overview of cyclodextrin chemistry. Chemical Reviews, 98(5), 1743-1754.

Szente, L., \& Szejtli, J. (2004). Cyclodextrins as food ingredients. Trends in Food Science \& Technology, 15, 137-142.

Tao, F., Hill, L. E., Peng, Y., \& Gomes, C. L. (2014). Synthesis and characterization of $\beta$ cyclodextrin inclusion complexes of thymol and thyme oil for antimicrobial delivery applications. LWT - Food Science and Technology, 59, 247-255.

Uyar, T., \& Besenbacher, F. (2008). Electrospinning of uniform polystyrene fibers: The effect of solvent conductivity. Polymer, 49, 5336-5343.

Uyar, T., Hacaloglu, J., \& Besenbacher, F. (2009a). Electrospun polystyrene fibers containing high temperature stable volatile fragrance/flavor facilitated by cyclodextrin inclusion complexes. Reactive and Functional Polymers, 69(3), 145-150.

Uyar, T., Hacaloglu, J., \& Besenbacher, F. (2009b). Electrospinning of functional poly (methyl methacrylate) nanofibers containing cyclodextrin-menthol inclusion complexes. Nanotechnology, 20(12), 125703.

Uyar, T., Hacaloglu, J., \& Besenbacher, F. (2011). Electrospun polyethylene oxide (PEO) nanofibers containing cyclodextrin inclusion complex. Journal of Nanoscience and Nanotechnology, 11(5), 3949-3958.

Uyar, T., Hunt, M. A., Gracz, H. S., \& Tonelli, A. E. (2006). Crystalline cyclodextrin inclusion compounds formed with aromatic guests: Guest-dependent stoichiometries and hydration-sensitive crystal structures. Crystal Growth \& Design, 6(5), 1113-1119.

Uyar, T., \& Kny, E. (2017). Electrospun materials for tissue engineering and biomedical applications: Research, design and commercialization. Woodhead publishing series in biomaterialsElsevier (ISBN: 9780081010228).

Wen, P., Wen, Y., Zong, M. H., Linhardt, R. J., \& Wu, H. (2017). Encapsulation of bioactive compound in electrospun fibers and its potential application. Journal of Agricultural and Food Chemistry, 65(42), 9161-9179.

Wendorff, J. H., Agarwal, S., \& Greiner, A. (2012). Electrospinning: Materials, processing and applications. Weinheim: John Wiley \& Sons.

Yalkowsky, S. H., He, Y., \& Jain, P. (2016). Handbook of aqueous solubility data. CRC press.

Yanishlieva, N. V., Marinova, E. M., Gordon, M. H., \& Raneva, V. G. (1999). Antioxidant activity and mechanism of action of thymol and carvacrol in two lipid systems. Food Chemistry, 64(1), 59-66. 